\title{
Actualización en manejo de Alergia a la proteína de leche de vaca: fórmulas lácteas disponibles y otros brebajes
}

\author{
Update on management of cow's milk protein allergy: Available milk formulas and \\ other juices
}

\section{Camila Cordero R. ${ }^{\mathrm{a}}$, Francisca Prado S. ${ }^{\mathrm{a}}$, Paulina Bravo J. ${ }^{\mathrm{b}}$}

aecadas de Pediatría, Universidad de los Andes

bPediatra, Especialista en Nutrición, Profesor Asistente Pediatría Universidad de los Andes. Clínica Santa María

Recibido el 9 de enero de 2018; aceptado el 3 de abril de 2018

\section{Resumen}

La alergia a la proteína de leche de vaca (APLV) es una enfermedad frecuente, con una prevalencia entre $2-7 \%$, cifras que van en aumento. Se caracteriza por una reacción alérgica a una o más proteínas de la leche de vaca. No existen manifestaciones clínicas patognomónicas, y éstas dependerán del tipo de reacción inmunológica involucrada. Una buena aproximación diagnóstica evita el sub y sobre diagnóstico y por lo tanto, sub y sobre tratamiento. El tratamiento de la APLV es la eliminación de la proteína de leche de vaca de la dieta. Una dieta de restricción en un niño que no la requiere o que ha desarrollado tolerancia, puede alterar el crecimiento, la calidad de vida y producir costos innecesarios. El objetivo de esta actualización es presentar las diferentes fórmulas y brebajes usados en Chile para tratar la APLV en aquellos casos en que no sea posible la lactancia materna con dieta de exclusión. Para ello se revisó la composición nutricional, ingredientes y otras características relevantes de todas aquellas fórmulas o brebajes que se comercializan en Chile como tratamiento de APLV. La información se obtuvo desde los distribuidores o vendedores oficiales, o en su defecto, desde las páginas web oficiales. Se puede concluir que existen y se usan múltiples fórmulas y brebajes para el tratamiento de APLV, no todas ellas del todo adecuadas desde el punto de vista nutricional y de seguridad. Conocerlas en detalle ayudará al pediatra a indicarlas de manera más informada de acuerdo a sus beneficios y sus carencias para el manejo adecuado de esta patología.

\section{Abstract}

Cow's milk protein allergy (CMPA) is a common disease with a prevalence of 2-7\%, increasingly so. It is characterized by an allergic reaction to one or more cow's milk proteins. There are not pathognomonic clinical symptoms, and these will depend on the type of immune reaction involved. A good diagnostic approach avoids under and over diagnosis and, therefore, under and over treatment. The
Palabras clave: Alergia alimentaria; proteína de la leche de vaca; fórmulas lácteas, brebajes

\section{Keywords:}

Food allergy; cow's milk protein; milk formulas 
CMPA treatment is the elimination of cow's milk protein from the diet. A restricted diet in a child does not require it or who has developed tolerance can alter growth, quality of life, including unnecessary costs. The objective of this review is to present the different milk formulas available in Chile to treat CMPA in those cases where breastfeeding with exclusion diet is not possible. For this purpose, nutritional composition, ingredients and other relevant characteristics of all the milk formulas and juices marketed in Chile as CMPA treatment were reviewed. The information was obtained from the official distributors or sellers or failing that, from the official websites. There are multiple milk formulas and beverages used for the treatment of CMPA, and not all of them are nutritionally or immunologically secure. Knowing them in detail will help the pediatrician to indicate them in a more informed way according to their benefits and their deficiencies for the proper management of this pathology.

\section{Introducción}

Las alergias alimentarias y la alergia a proteina de leche de vaca (APLV) son un problema de salud creciente $^{1,2}$. En estudios internacionales se desribe una prevalencia de $2-7,5 \% \%^{1,3}$, sin embargo en Chile no se cuenta con estudios de prevalencia de esta patología ${ }^{1,4}$ teniendo un peak de incidencia el primer año de vida, que cae a menos de $1 \%$ en mayores de 6 años ${ }^{2}$. Los principales alergenos en la infancia son el huevo y la proteína de leche de vaca (PLV). Las alergias alimentarias y específicamente la APLV se define como una reacción adversa que surge de una respuesta inmune específica y es reproducible con las siguientes exposiciones a la $\mathrm{PLV}^{2}$. Estas reacciones inmunes se clasifican en mediadas por IgE y no mediadas por $\operatorname{IgE}^{1-3}$. Las manifestaciones clínicas son inespecíficas, lo que dificulta su diagnóstico ${ }^{1-4}$. La APLV tiene un gran impacto médico, social y económico, para el paciente y su familia, pudiendo incluso las formas graves amenazar la vida ${ }^{1}$. El tratamiento se basa en la estricta eliminación de la PLV en la dieta, mediante la dieta de eliminación materna y/o fórmulas hipoalergénicas ${ }^{1-4}$, éstas últimas de alto costo ${ }^{1}$. Mantener una dieta de restricción en un paciente que no la requiere, ya sea por un diagnóstico incorrecto o porque ha desarrollado tolerancia, afecta el crecimiento, desarrollo y calidad de vida ${ }^{1,2}$.

Actualmente en el mercado existen muchas fórmulas y jugos o brebajes industriales que se indican para la alimentación de estos pacientes, sin embargo, no todos ellos cumplen los criterios para ser catalogados como fórmulas terapéuticas o hipoalergénicas, y por otro lado, algunos no se encuentran adaptadas para su uso en lactantes y no suplen sus requerimientos nutricionales $^{1,2}$. Por esto es fundamental conocer las características y limitaciones nutricionales de las fórmulas lácteas y otros brebajes disponibles para el manejo de la APLV. El objetivo de este artículo es presentar una revisión actualizada de las propiedades nutricionales, ventajas y desventajas de los productos actualmente disponibles y usados por la población.

\section{Manifestaciones clínicas y diagnóstico de APLV}

El diagnóstico de la mayoría de las alergias alimentarias es clínico, por lo que se debe realizar una completa historia y examen físico. De relevancia son la edad de inicio, tipo de síntomas y su frecuencia, tiempo entre la ingestión y aparición de síntomas, tipo de alimentación, antecedentes personales y familiares de atopía. La dermatitis atópica es una comorbilidad frecuente en estos pacientes ${ }^{1-4}$.

El riesgo de atopía aumenta si un padre o hermano tienen enfermedad atópica (20-40 y 25-35\% respectivamente) y es aún mayor si ambos padres son atópicos (40-60\%).

Los lactantes alimentados con lactancia materna exclusiva (LME) tienen menor riesgo de desarrollar APLV y otras enfermedades atópicas teniendo además formas menos severas durante la infancia, en comparación a los alimentados con fórmula o alimentación mixta $^{1,3,4}$. Esto puede estar relacionado con que la leche materna (LM) tiene 100.000 veces menos proteína de leche de vaca y contiene inmunomoduladores. Además, aquellos niños alimentados con lactancia materna exclusiva (LME) tienen una flora intestinal distinta a los alimentados con fórmula. Debido a esto y a todos los beneficios de la LM, esta debe promoverse como prevención primaria de $\mathrm{APLV}^{2}$.

La mayoría de las veces, pero no siempre, los síntomas aparecen durante las primeras semanas de la introducción de la PLV en la dieta ${ }^{1,3}$. Los sistemas más frecuentemente involucrados son: gastrointestinal (50-60\%), dermatológico (50-60\%) y respiratorio $(20-30 \%)^{1-3}$. El compromiso de 2 o más sistemas aumenta la probabilidad de APLV ${ }^{2}$. Como se menciona previamente, los síntomas y signos dependen de la reacción inmunológica involucrada, pudiendo ser reacciones mediadas por IgE y no mediadas por $\operatorname{IgE}^{1-3}$. Aunque puede haber combinación de ambos mecanismos en un mismo paciente ${ }^{2}$. 


\section{A. Reacciones mediadas por IgE o manifestaciones inmediatas:}

Ocurren entre minutos a 2 horas luego de la ingesta. Las manifestaciones gastrointestinales incluyen el síndrome de alergia oral y alergia gastrointestinal mediada (vómitos recurrentes). Las respiratorias involucran inicio brusco de obstrucción bronquial, o rinitis secundaria a la ingesta o inhalación de LV. Las dermatológicas son urticaria, eritema, angioedema y prúrito. La forma más severa corresponde a la anafilaxia.

\section{B. Reacciones no mediadas por IgE o manifestaciones tardías:}

Se manifiestan desde $48 \mathrm{~h}$ a una semana desde la ingesta. Las más frecuentes son gastrointestinales como vómitos, diarrea, rectorragia, constipación con o sin eritema perioral, cólicos e irritabilidad persistente. Las formas severas incluyen mal incremento pondo-estatural, rechazo alimentario, anemia ferropénica con o sin rectorragia asociada, enteropatía alérgica perdedora de proteínas con hipoalbuminemia y enterocolitis alérgica severa. Si una o más manifestaciones ocurren y no son explicadas por otra causa, se debe considerar APLV como alternativa diagnóstica ${ }^{1-3}$.

Errazuriz G., et al. en un estudio nacional reciente describe las características clínicas de estos pacientes donde se observó una alta frecuencia de antecedentes familiares de atopia, las manifestaciones más frecuentes fueron las gastrointestinales (reflujo, cólicos y rectorragia). Más de la mitad de los pacientes (61\%) tuvieron 2 o más síntomas como manifestación clínica, concordante con la literatura internacional ${ }^{4}$.

\section{Diagnósticos diferenciales de APLV}

Se debe considerar condiciones que pueden coexistir en el mismo paciente, como el reflujo gastroesofágico y los cólicos además de tener en cuenta que mecanismos no inmunológicos pueden simular una APLV (intolerancia a la lactosa, reacciones a medicamentos o ingesta de tóxicos). Dentro de los diagnósticos diferenciales se incluyen: alteraciones anatómicas del tracto gastrointestinal, errores innatos del metabolismo, enfermedad celíaca, otras enteropatías, insuficiencia pancreática ( $\mathrm{p}$ ej. fibrosis quística), reacciones adversas no inmunológicas, intolerancia a la lactosa, intolerancia a la fructosa, reacciones alérgicas a otros alimentos, etc. ${ }^{2,3}$.

\section{Procedimientos diagnósticos}

Si los síntomas y signos son sugerentes y no son explicados por otra causa, se debe considerar el diag- nóstico de APLV. En la actualidad no existe ninguna prueba diagnóstica que permita confirmar o descartar la APLV por lo que en la mayoría de los casos se debe realizar una dieta de eliminación y una contraprueba de provocación oral, que corresponden al Gold Standard de diagnóstico en niños con manifestaciones leves a moderadas ${ }^{1-3}$. La duración de la dieta de eliminación es variable y debe ser lo más corta posible pero lo suficientemente prolongada como para juzgar si los síntomas se resolvieron o no. El rango es de 3-5 días en pacientes con manifestaciones inmediatas y 1-2 semanas para las manifestaciones tardías, pudiendo prolongarse hasta 4 semanas en presencia de síntomas gastrointestinales ${ }^{2,3}$. La Guía Clínica APLV nacional recomienda la dieta de eliminación durante 4-6 semanas ${ }^{1}$.

Tanto la dieta de eliminación como la contraprueba se pueden sub-clasificar según el tipo de alimentación del paciente:

\section{LME}

Se debe eliminar de la dieta materna toda proteína láctea incluida las trazas de ésta. Si el paciente mejora durante la dieta de eliminación el diagnóstico debe confirmarse con una contraprueba de provocación oral y en caso contrario, considerar otro diagnóstico ${ }^{1-3}$. La contraprueba de provocación oral debe realizarse de manera estandarizada y bajo supervisión médica. El Gold Standard es la prueba doble ciego (tanto médicos como padres no saben que alimentación está recibiendo el paciente) sin embargo, resulta difícil de realizar y $\operatorname{costosa}^{2}$, por lo que la prueba abierta es adecuada como primera aproximación diagnóstica. La madre debe reintroducir la proteína láctea a su dieta durante una semana y evaluar la reaparición de síntomas. Si estos no reaparecen considerar que no existe APLV. Si los síntomas reaparecen se confirma el diagnóstico y la madre debe mantener una dieta estricta de eliminación de $\mathrm{PLV}^{1-3}$.

\section{Fórmula o alimentación mixta}

En pacientes menores de 6 meses que sólo estén recibiendo fórmula láctea, esta debe ser reemplazada por una fórmula hipoalergénica. En los mayores de 6 meses, idealmente se debe evitar todo otro alimento distinto a la fórmula hipoalergénica. De no ser posible se debe indicar una dieta con un número limitado de alimentos e introducirlos uno a la vez, con consejería nutricional. La fórmula inicial debe ser una extensamente hidrolizada (FEH) y evaluar si hay mejoría de los síntomas.

En el caso de mantener los síntomas o que sean severos, tener presente que ciertos lactantes pueden reaccionar a residuos alérgenos de las $\mathrm{FEH}$, pudiendo ser una razón de su falla. En estos casos se permite indicar una fórmula aminoacídica (FA). Si no existe mejoría con esta fórmula, se debe evaluar adherencia a la dieta 
o dudar del diagnóstico. En los pacientes que presentaron mejoría clínica con la alimentación con FEH y FA, al igual que los alimentados con LME, se debe realizar una contraprueba de provocación oral ${ }^{1-3}$.

\section{Tipo de fórmula y dosis:}

Durante el primer año de vida, la prueba de provocación oral debe realizarse con una fórmula de inicio o continuación. La leche de vaca fresca pasteurizada no modificada puede usarse luego del año de vida. La dosis inicial debe ser menor a la que produce síntomas y se debe aumentar progresivamente de la siguiente forma: $0,1,0,3,1,10,30,100 \mathrm{~mL}$, en intervalos de 30 minutos ${ }^{2}$.

Si no ocurre ninguna reacción, se debe indicar alimentación con fórmula láctea en base a leche de vaca: $200 \mathrm{~mL} /$ día como mínimo, durante 2 semanas.

Realizar en ambiente hospitalario en las siguientes circunstancias:

1. Historia de reacción inmediata

2. Reacción impredecible (lactantes con IgE positiva que nunca han sido expuestos a PLV o lo han hecho por un corto periodo de tiempo).

3. Eczema atópico severo. En los pacientes con reacciones dérmicas documentar de manera objetiva (p. ej escalas de severidad validadas como SCORAD index) las condiciones de la piel, antes y después del procedimiento ( 24 y 48 horas después). En pacientes con diarrea documentar frecuencia y consistencia ${ }^{2}$.

\section{Métodos diagnósticos de laboratorio}

- IgE específica y prick test: La positividad de estos exámenes indica sensibilización y que el mecanismo es mediado por IgE, por lo que deben correlacionarse con la historia clínica y pruebas diagnósticas de eliminación y provocación oral. Mientras mayores son los títulos de IgE específica y mayor es el diámetro de la prueba cutánea, mayor es la probabilidad de APLV y persistencia de la alergia ${ }^{1-3}$.

- Test de parche, IgE total y test intradérmicos: El test de parche pudiera tener alguna utilidad en pacientes con IgE específica negativa, sin embargo, ni el procedimiento (preparación y aplicación del antígeno) ni los resultados se encuentran estandarizados. Hasta el momento, su interpretación es difícil y subjetiva, por lo que se desaconseja su uso en forma rutinaria. La determinación de $\mathrm{IgE}$ total y la relación entre IgE total/específica no son beneficiosos por sobre la IgE específica. Los test intradérmicos tienen riesgo de reacciones sistémicas en niños altamente sensibilizados.

- IgG: Tanto su determinación como la de subclases no tienen rol diagnóstico ${ }^{2}$.
- Endoscopia e histología: Apropiado en niños con síntomas severos e inexplicados, con falla de crecimiento y anemia ferropénica, sin embargo, su valor radica en la búsqueda de diagnósticos diferenciales más que la confirmación diagnóstica de APLV, ya que los hallazgos macroscópicos y microscópicos de atrofia de la mucosa e infiltración eosinofílica no son sensibles ni específicos. Debe correlacionarse con los antecedentes clínicos ${ }^{1,2}$.

\section{Tratamiento}

El manejo de esta entidad se basa en la estricta evitación de la PLV y depende del tipo de alimentación que recibe el lactante.

\section{Alimentación con LME}

La madre debe eliminar de su dieta toda proteína láctea ${ }^{1-3}$. Además, se deben revisar todos los alimentos y rótulos de medicamentos que recibe tanto la madre como el lactante. La PLV puede denominarse como: leche, suero de leche, sólidos de leche, caseína, caseinato, lactoalbúmina, proteína láctea ${ }^{1}$. En casos severos que no respondan a tratamiento, se considerará eliminar otros productos de la dieta materna (carne de vacuno, nueces, maní, mariscos, soya $)^{1,3}$ y suplementar al lactante con hierro, zinc, vitamina D y ácidos grasos omega 3.

A los 6 meses, se introducirá la alimentación complementaría. Al introducir sólidos, debe ser uno por vez y en pequeñas cantidades ${ }^{4}$. Retrasar la introducción de alimentos altamente alérgenos como el huevo, pescado y gluten no ha mostrado beneficios en la prevención de alergias, por lo que se desaconseja, excepto si existe alergia probada a uno de ellos ${ }^{2,4}$.

Mientras la madre se encuentra bajo dieta de eliminación, debe recibir consejería nutricional para evitar desbalances nutricionales y debe recibir suplementación de calcio (1.000 mg al día, dividido en 2 tomas) y vitamina D (800 UI/día).

\section{Alimentados con fórmula o alimentación mixta}

Se deben evitar todos los productos lácteos de la dieta. Estos pacientes deben recibir una fórmula terapéutica para APLV. En primera instancia se prescribirá una FEH. Si no existe respuesta satisfactoria se debe indicar una FA. En niños con manifestaciones severas y de hipersensibilidad inmediata tipo anafilaxia, se indicará como primera opción una $\mathrm{FA}^{1-3}$.

\section{Fórmulas}

\section{Fórmulas indicadas en APLV}

La Asociación Americana de Pediatría (AAP) define a las fórmulas terapéuticas para el manejo de la APLV como aquellas que no provoquen reacción en un $90 \%$ de los lactantes y niños con APLV confirmada, 
con un intervalo de confianza de 95\% en ensayos clínicos randomizados doble ciego ${ }^{5}$.

- Fórmulas de hidrolizados proteícos: son fórmulas adaptadas para su uso en lactantes. Han sufrido un proceso de pre-digestión mediante hidrólisis enzimática, tratamiento térmico y ultrafiltración ${ }^{5,6}$. La fuente proteica es la caseína, suero o ambas. La hidrólisis da como resultado, péptidos de cadena corta $^{5}$. Para ser consideradas FEH el peso molecular de los péptidos debe ser menor a 3000 Daltons $(\mathrm{Da})^{2}$. Los Hidratos de carbono son polímeros de glucosa y algunas son combinación de polímeros de glucosa y sacarosa. Contienen una mezcla de aceites vegetales similar a las fórmulas estándar aportando ácidos grasos esenciales ${ }^{5}$, presentan suplementación de micronutrientes como cualquier fórmula de inicio o continuación.

- Fórmulas aminoacídicas: son fórmulas sintéticas en base a aminoácidos libres como única fuente de nitrógeno ${ }^{2}$. Contienen maltodextrina, triglicéricos de cadena media (MCT) y ácidos grasos de cadena larga para evitar el déficit de ácidos grasos esenciales. Todas son libres de lactosa ${ }^{6}$. Constituyen la mejor opción para niños que reaccionan a las FEH y se consideran de primera línea (con evidencia limitada) en pacientes con reacciones anafilácticas o enteropatía con hipoalbuminemia y falla de crecimiento $^{2}$.

\section{Fórmulas inadecuadas para la APLV}

- Fórmulas parcialmente hidrolizadas (FPH): contiene péptidos con un peso molecular $<5.000 \mathrm{Da}$, por lo que su alergenicidad no es nula, ya que conservan algunos epítopes de péptidos capaces de causar reacciones alérgicas. Pueden ser utilizadas para la prueba de provocación oral cuando se presume tolerancia ${ }^{2,5,6}$.

- Leches de otros mamíferos: la mayoría de los pacientes no toleran la leche de cabra y oveja, sin embargo, algunos toleran la leche de camello, cerdos, renos, yegua y burra. Esto puede deberse a que algunos mamíferos se encuentran relacionados genéticamente y por esto, tienen similitud en la expresión de la proteína de la leche. Estudios in vitro han mostrado amplia reactividad cruzada entre leche de vaca, cabra y oveja y reacción débil contra leche de burra y yegua ${ }^{7}$. No todas se encuentran pasteurizadas, la mayoría no están adaptadas y no cumplen con los requisitos nutricionales de lactantes 8 .

- Jugos de almendras, avellanas, arroz, soya, coco y otros vegetales: son inadecuadamente llamadas "leches" pues no provienen de la glándula mamaria ${ }^{2}$ por lo que no se encuentran indicadas para su uso en lactantes, ya que no suplen sus necesidades nutricionales ${ }^{1,2}$. En mayores de 2 años hay que considerar que contienen más o menos calcio depen- diendo si son fortificados, pero su biodisponibilidad es desconocida y se presume bastante baja por la menor o nula cantidad de proteína vegetal asociada y la presencia elevada de fitatos no contribuye a una buena absorción. Todas son hipocalóricas.

- Fórmula de soya: son fórmulas adaptadas para el uso en lactantes, a diferencia de los jugos de soya. El componente proteico es la proteína aislada de soya. En relación con la leche de vaca, tienen mayor concentración de proteínas $(2,4$ a 2,8 g/100 mL) y contiene suplementos de aminoácidos (metionina, taurina, carnitina) para mejorar su valor biológico. Los hidratos de carbono son maltodextrina, polímeros de glucosa y/o sacarosa, todas son libres de lactosa. Los lípidos son de origen vegetal (aceite de soya, maíz, coco), algunas contienen MCT y adición de ARA y DHA. La biodisponibilidad (por su contenido de fitatos) de calcio, zinc, fierro, magnesio fósforo es menor que las fórmulas de inicio. Es por esto que la concentración de calcio y fósforo es un $20 \%$ mayor y tienen adición de zinc y fierro. Asimismo, contiene altas concentraciones de aluminio, que también compiten con la absorción de calcio ${ }^{5,6}$. Se ha reportado una reacción cruzada a soya en 10$30 \%$ de los pacientes con $\mathrm{APLV}^{3,8}$. En lactantes con enteropatía no mediada por IgE tienen una tasa de $30-64 \%$ y $8-14 \%$ en los pacientes con reacciones mediadas por $\operatorname{IgE}^{5}$.

- Fórmulas en base a arroz: las fórmulas hidrolizadas de arroz son relativamente nuevas, por lo que no se encuentran como alternativa terapéutica en las guías publicadas. Su eficacia clínica parece ser excelente. El contenido de arsénico puede constituir un problema, por lo que el etiquetado debe especificar que se encuentra dentro de los límites de seguridad. Sólo serían recomendables ante las escasas situaciones en que hay reacciones a las fórmulas aminoacídicas ${ }^{8}$. No está disponible en Chile pero puede importarse.

A partir de junio del 2017 el Ministerio de Salud entrega en forma gratuita fórmulas hipoalergénicas (FEH y FA) a niños menores de 2 años diagnósticados con APLV y que pertenezcan al sistema público de salud. Para acceder a este beneficio se requiere cumplir los criterios diagnósticos en base a la Guía Clínica Ministerial, realizado por un especialista. El hospital al que el paciente pretenece será el encargado de la entrega del alimento, siendo necesario acreditar los controles de salud e inmunizaciones al día?.

Para revisar en detalle la composición de las fórmulas y brebajes disponibles (a nivel nacional e internacional), se anexa una tabla de composición de éstas (adecuadas e inadecuadas) para el manejo de la APLV. (Tabla 1). 


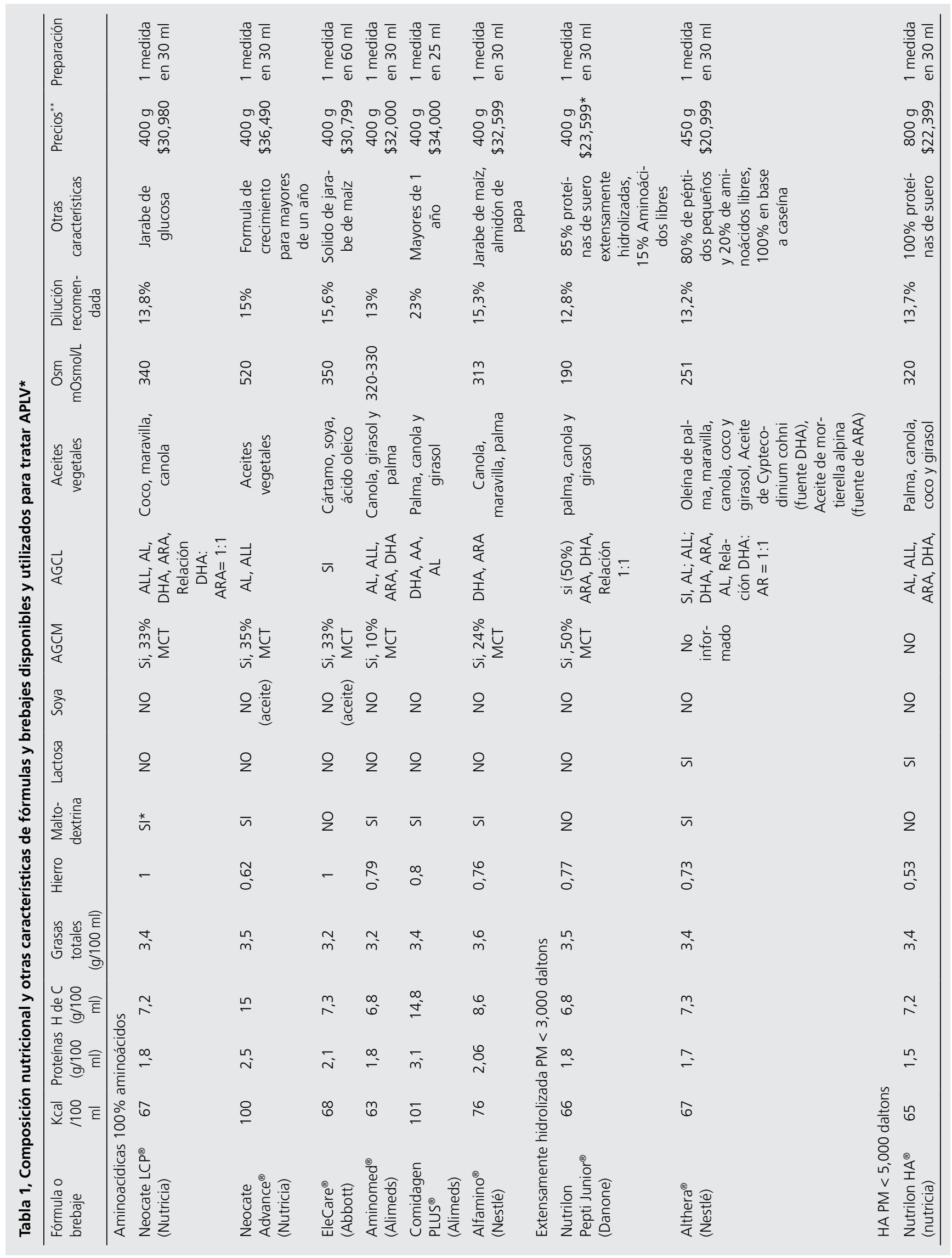




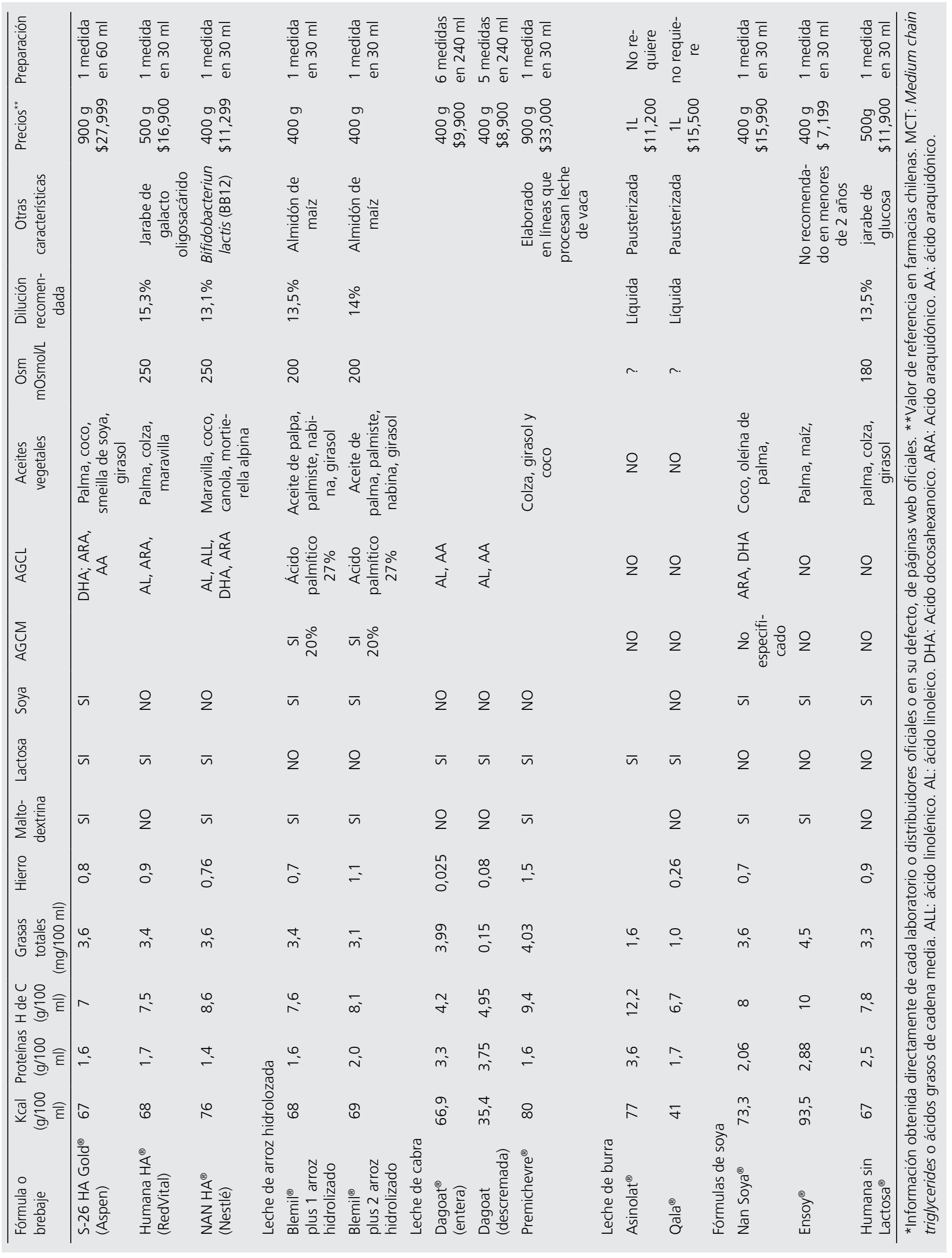




\section{Reevaluación y desarrollo de tolerancia}

El primer enfrentamiento de alta se realizará a los 12 meses de vida o tras 6 meses del diagnóstico, y si no existe desarrollo de tolerancia se evaluará cada 6 meses según evolución. En caso de formas severas y reacciones inmediatas se realizará bajo supervisión médica e indicación de subespecialista ${ }^{1-3}$.

De utilidad es la valoración de los test de IgE específica para determinar el momento de introducción de $\mathrm{PLV}^{2}$, teniendo mejor pronóstico en relación con tiempo de desarrollo de tolerancia aquellos con IgE negativa, comparadas a aquellos con resultado positi$\mathrm{vo}^{3}$. Es primordial determinar la tolerancia a la PLV, para evitar prolongar dietas restrictivas, que afectan el crecimiento y desarrollo del niño y que por otra parte, comprometen el estado nutricional de la madre que está lactando ${ }^{2}$.

\section{Conclusiones}

La APLV es una entidad frecuente en la población pediátrica y se encuentra en aumento. No existen signos ni síntomas patognomónicos, por lo que es de suma importancia para su diagnóstico la sospecha clínica y una completa anamnesis y examen físico. Las manifestaciones clínicas se pueden clasificar según el mecanismo inmunológico involucrado, siendo de vital importancia las reacciones de tipo anafilácticas.

Debido a la baja especificidad de sus síntomas, es de relevancia la correcta aproximación y confirmación diagnóstica mediante la dieta de eliminación y contraprueba de provocación oral, para evitar tanto falsos positivos y negativos que nos lleven a indicar medidas de tratamiento nutricionalmente inadecuadas para el paciente, con riesgo de afectar su adecuado crecimiento y desarrollo y también para la madre que se encuentra lactando, perjudicando su estado nutricional, causando angustia y costos innecesarios en la familia afectada. Ningún examen de laboratorio hasta el momento permite confirmar o descartar el diagnóstico de APLV, por lo que su solicitud e interpretación debe realizarse con prudencia.

El tratamiento consiste en la estricta evitación de la PLV: en lactantes alimentados con LME, la madre debe cumplir la dieta de eliminación y en pacientes que se alimenten con fórmula, indicar una fórmula terapéutica para APLV, que son las fórmulas extensamente hidrolizadas y en su defecto, fórmulas aminoacídicas. Resultan inadecuadas tanto nutricionalmente como por el riesgo de reacciones cruzadas las fórmulas parcialmente hidrolizadas, jugos industriales o caseros de vegetales y las leches de otros mamíferos. Como se describe en la Guía ESPGHAN 2012 de diagnóstico y manejo de APLV, en la mayoría de los casos el pronóstico es bueno, con desarrollo de tolerancia en un $50 \%$ de los casos luego del primer año de vida, $>75 \%$ a los 3 años y $>90 \%$ a los 6 años de vida.

\section{Conflicto de intereses}

Los autores declaran no tener conflicto de intereses.

\section{Referencias}

1. Guía clínica Alergia a proteína de leche de vaca. Chile, MINSAL, 2012.

2. Koletzko S, Niggemann B, Arato A, et al. Diagnostic Approach and Management of Cow's-Milk Protein Allergy in Infants and Children: ESPGHAN GI Committee Practical Guidelines. J Pediatr Gastroenterol Nutr. 2012;55:221-9.

3. Vandenplas Y, Brueton M, Dupont C, et al. Guidelines for the diagnosis and management of cow's milk protein allergy in infants. Arch Dis Child. 2007; 92:902-8.

4. Errázuriz G, Lucero $\mathrm{Y}$, Ceresa $\mathrm{S}$, González M, Rossel M, Vives A. Características clínicas y manejo de lactantes menores de 1 año con sospecha de alergia a proteína de leche de vaca. Rev Chil Pediatr. 2016;87(6):449-54.

5. Martínez A, Ballew M. Infant formulas. Pediatrics. 2011;32:179-89.

6. Martín-Aragón M, Marcos Elena. Fórmulas lácteas especiales. Farmacia profesional. 2008; 22:42-7.
7. Jarvinen-Seppo M. Milk allergy: Management. Up to date. http://www. uptodate.com, última visita 16/10/2017.

8. Vandenplas Y. Prevention and Management of Cow's Milk Allergy in Non-Exclusively Breastfed Infants. Nutrients 2017;9:731.

9. MINSAL. Ministerio de Salud inicia entrega de alimentación complementaria a niños y niñas menores de 2 años alérgicos a la proteína de leche de vaca. Junio 2017. http://web.minsal.cl, última visita 12/11/2017. 